7 Noble P, Rodger S. Violence by psychiatric in-patients. Br J Psychiatry 1989; 155: 384-90.

8 Paavola P, Tiihonen J. Seasonal variation of seclusion incidents from violent and suicidal acts in forensic psychiatric patients. Int J Law Psychiatry 2010; 33: 27-34.

9 Rangecroft ME, Tyrer SP, Berney TP. The use of seclusion and emergency medication in a hospital for people with learning disability. $\mathrm{Br}$ Psychiatry 1997; 170: 273-7.

10 Soloff $P$, Turner SM. Patterns of seclusion: a prospective study. J Nerv Ment Dis 1981; 169: 37-44.

11 Thompson $\mathrm{P}$. The use of seclusion in psychiatric hospitals in the Newcastle area. Br J Psychiatry 1986; 149: 471-4.

12 Fisher WA. Elements of successful restraint and seclusion reduction programs and their application in a large, urban, state psychiatric hospital. J Psychiatr Pract 2003; 9: 7-15.
13 Smith GM, Davis RH, Bixler EO, Lin HM. Pennsylvania State Hospital system's seclusion and restraint reduction program. Psychiatr Serv 2005; 56: 1115-22.

14 Keski-Valkama A, Sailas E, Eronen M, Koivisto A-M, Lönnqvist J, Kaltiala-Heino R. A 15-year national follow-up: legislation is not enough to reduce the use of seclusion and restraint. Soc Psychiatry Psychiatr Epidemiol 2007; 42: 747-52.

15 Flannery RB, Juliano J, Cronin S, Walker A. Characteristics of assaultive psychiatric patients: fifteen-year analysis of the Assaulted Staff Action Program (ASAP). Psychiatr Quart 2006; 77: 239-49.

16 Currier G, Farley-Toombs C. Datapoints: use of restraint before and after implementation of the new HCFA rules. Psychiatr Serv 2002; 53: 138.

17 Donovan A, Plant R, Peller A, Siegel L, Martin A. Two-year trends in the use of seclusion and restraint among psychiatrically hospitalized youths. Psychiatr Serv 2003; 54: 987-93.

18 Livingstone A. Seclusion Practice: A Literature Review. Victorian Quality Council and Chief Psychiatrist's Quality Assurance Committee, 2007.

\title{
Predictors for retention in treatment with a UK community-based naltrexone programme for opioid dependence
}

\author{
Zubair A. Chaudhry, Javaid Sultan, ${ }^{2}$ Farrukh Alam ${ }^{1}$
}

The Psychiatrist (2012), 36, 218-224, doi: 10.1192/pb.bp.111.035063

${ }^{1}$ Central and North West London NHS Foundation Trust; ${ }^{2}$ Berkshire Healthcare NHS Foundation Trust

Correspondence to Zubair A Chaudhry (zubair.chaudhry@nhs.net)

First received 20 Apr 2011, final revision 17 Oct 2011, accepted 2 Dec 2012
Aims and method To evaluate the efficacy of naltrexone maintenance therapy in a community-based programme for opioid-dependent patients and to identify predictors for longer-term retention in treatment. A retrospective case-note study was conducted in 142 people dependent on opioids who had undergone detoxification and maintained adherence to naltrexone treatment for a minimum of 4 weeks. Social and clinical demographic factors during treatment were recorded using a standardised naltrexone monitoring scale. Efficacy was measured as retention in treatment, and potential predictors were examined using regression analysis.

Results Although there was overall low retention of patients in treatment, $55.6 \%$ of the patients remained in treatment for 4-8 weeks, and $29.6 \%$ of the patients remained in treatment for 17 weeks or more. Enhanced long-term retention in treatment was associated with Asian or other minority ethnic status, employment, parental supervision of naltrexone administration, less boredom, short duration of addiction, younger age, low alcohol intake and no cannabis use in univariate analyses. Short duration of opioid dependence syndrome (3 years) and low alcohol intake $(<10$ units/week) were significant independent predictors for longer-term retention in treatment in subsequent multivariate analysis.

Clinical implications Low alcohol intake and shorter duration of addiction were significant independent predictors for longer-term retention in treatment, but retention rates for naltrexone remain low overall. Additional psychosocial support may be needed to address these issues.

Declaration of interest None.
The National Institute for Health and Clinical Excellence (NICE) has reported that naltrexone is recommended as a treatment option in detoxified formerly opioid-dependent people who are highly motivated to remain on an abstinence programme. Naltrexone should be administered only under adequate supervision and after fully informing the patient of the potential adverse effects of treatment. Naltrexone should be given as part of a programme of supportive care. 
The effectiveness of naltrexone in preventing opioid misuse should be reviewed regularly, and discontinuation of naltrexone treatment should be considered if there is evidence of such misuse. The NICE committee was convinced of the clinical effectiveness of naltrexone treatment in a selected, highly motivated group of people. The NICE committee concluded that for people who preferred an abstinence programme, who were fully informed of the potential adverse effects and benefits of treatment, and who were highly motivated to remain on treatment, naltrexone treatment would fall within acceptable cost-effectiveness limits. ${ }^{1}$

According to Luty, naltrexone completely blocks the effects of opiates and acts as an 'insurance policy' against opiate use. ${ }^{2}$ Naltrexone can precipitate acute withdrawal and should be used only following abstinence from all opioids, including methadone. Treatment can be given daily or three times a week. Luty argues that naltrexone has not proven effective in treatment settings, although some investigators appear to have viewed it as a direct alternative to methadone rather than as an approach that can enable a completely opiate-free state; for example, in one trial, only 15 of 300 patients chose naltrexone instead of detoxification or methadone maintenance, and of those 15 participants, only 3 continued naltrexone for more than 2 months. ${ }^{2}$

Naltrexone is an opioid receptor antagonist used primarily as maintenance treatment in the management of opioid or alcohol dependence. As an antagonist, it does not provoke a biological response when it binds to the opioid receptors, but instead it blocks or dampens agonistmediated responses, blocking the euphoric effects of heroin and other opioids, helping patients to maintain abstinence from opioid drugs. ${ }^{3}$ A number of systemic reviews and meta-analyses have examined the efficacy of naltrexone in people who are dependent on opioid drugs. These reviews have concluded that naltrexone appears to have some benefit in the management of opioid dependence; however, the heterogeneity of trials makes objective evaluation difficult. ${ }^{3-7}$

The aim of this study was to use a retrospective casenote study to rigorously assess and identify other potential predictors for longer-term retention on naltrexone maintenance therapy. The case notes were also used to evaluate the overall rate of retention in treatment in a large UK community drug clinic.

\section{Method}

\section{Patients and treatment protocol}

We used a retrospective case-note study of 142 people treated with naltrexone therapy following opioid detoxification between April 1997 and December 2006. The protocol received approval from the local research ethics committee. All the patients included in the study were dependent on opioids and had completed successful opioid detoxification. Patients attending the clinic were assessed for suitability for naltrexone treatment. Consent for commencement of naltrexone therapy was obtained from all patients, their general practitioners (GPs) were informed, and each patient was given a naltrexone card to provide information to other health professionals.

Patients were seen every 2 weeks for the first month of treatment, and then every month. All patients completed a naltrexone monitoring scale (online Fig. DS1) at each visit. All patients who remained on naltrexone treatment had routine blood tests (full blood count, urea and electrolytes, liver function tests) every 3 months, or more frequently if indicated. Participants were assessed and followed up at the local community drug treatment centre. An afternoon session was dedicated as an 'abstinence promotion clinic', which involved a naloxone challenge to initiate naltrexone, reviewed patients prescribed naltrexone, asked patients to complete a naltrexone monitoring scale, and carried out random urine drug screening for all patients included in the study. Urine drug screening was conducted every 2 weeks, and liver function tests were conducted as indicated (every 6-12 weeks). Liaison with GPs and local providers and partners such as Drug and Alcohol Action Team was important to further develop a strategy for substance misuse treatment, in addition to primary prevention. The initial results of the study were fed back to patients who regularly attended follow-up appointments.

\section{Study procedures}

Clinical notes were examined for all eligible patients receiving naltrexone therapy following opioid detoxification during the study period of April 1997 to December 2006. The duration of the study allowed a large cohort to be recruited, thus increasing the power calculation. The following inclusion criteria were used:

- patients aged 18-65 years who were dependent on opioids and who had successfully completed detoxification

- resident of Ealing borough of London

- consent obtained before starting treatment with naltrexone therapy

- liver function tests within normal limits.

The following exclusion criteria were used:

- history of previous hypersensitivity

- on naltrexone for less than 3 weeks

- refusal to complete naltrexone monitoring scale questionnaire

- alcohol misuse or dependence

- abnormal liver biochemistry

- pregnant or planning pregnancy in the near future (all female participants had a pregnancy test before starting naltrexone).

Demographic details, family and relationship details and employment status were collected at the start of naltrexone treatment. A standardised questionnaire (naltrexone monitoring scale) was used to gather information about anxiety and depression symptoms, cravings, sleep disturbances, illicit drug use, and alcohol use and misuse at each medical out-patient assessment. Each category was scored on a scale of 0 (absent) to 10 (severe).

To assess the success of treatment and to evaluate predictors for retention in naltrexone treatment and successful abstinence from opioids, retention was categorized into three stages: 
- Stage I: 1-8 weeks

- Stage II: 9-16 weeks

- Stage III: 17 weeks.

\section{Statistical methods}

All relevant clinical case notes were reviewed for eligibility and the demographic details were anonymised to maintain patient confidentiality. We used SPSS version 10 for Windows for data entry and analysis.

The main efficacy outcome examined was whether or not patients progressed to stage III (treatment $\geqslant 17$ weeks). This was measured on a categorical scale as 'yes' or 'no'. The aim of the subsequent analysis was to examine which factors had an influence on this outcome.

At analysis, the scores from the naltrexone monitoring scale were simplified as follows:

- absent (0): symptoms not present, or normal, or no illicit drug use

- mild/low (1-3): mild symptoms or occasional illicit drug use (1-3 days/week)

- moderate (4-7): moderate symptoms or frequent illicit drug use (3-5 days/week)

- severe/high (8-10): severe or worst ever symptoms or daily illicit drug use (6-7 days/week).

The effect of each variable on the outcome (retention in treatment to stage III) was examined using logistic regression. The analysis of the data was performed in two stages. First, the individual effect of each variable was examined separately in a series of univariate analyses. Then the joint effects of the factors on the outcome were examined together in a multivariate analysis.

An advantage of the multivariate analysis was that the effect of each variable on the outcome is adjusted for the effect of the other variables, giving a better view of the underlying factors influencing the outcome. Only factors that showed evidence of a significant effect in the univariate analyses $(P<0.2)$ were included in the multivariate analysis. A backward selection procedure was used to determine the final model. This method involved removing non-significant variables from the analysis one by one until all remaining variables were statistically significant.

A number of the variables were measured on a categorical scale. As there were a relatively small number of participants in some groups, to increase the power of the study we combined some similar groups for the purposes of analysis.

\section{Results}

\section{Patients' characteristics}

Over the study period, 220 patients successfully achieved opioid detoxification and were prescribed naltrexone at the community drug treatment centre. Of these, 142 patients fulfilled the necessary criteria to be included in the study, and 78 patients were excluded from the study because of the exclusion criteria and insufficient data. The mean age of the study population was 26.4 years (range 17-61). The mean duration of addiction was 5.5 years (range 1-22). The 'typical' patient treated at the centre was an unmarried Asian male in his early 20s (Table 1).

\begin{tabular}{lc}
\multicolumn{2}{l}{ Table 1 Sociodemographic characteristics } \\
Variable & $n(\%)$ \\
\hline Age, years & \\
$\leqslant 21$ & $40(28.2)$ \\
$22-26$ & $50(35.2)$ \\
$27-31$ & $24(16.9)$ \\
$32-37$ & $12(8.5)$ \\
$38-42$ & $8(5.6)$ \\
$\geqslant 43$ & $8(5.6)$ \\
\hline Gender & \\
Male & $133(93.7)$ \\
Female & $9(6.3)$ \\
\hline Marital status & \\
Unmarried & $105(73.9)$ \\
Married & $31(21.8)$ \\
Not known & $6(4.2)$ \\
\hline Ethnic group & \\
White & $36(25.4)$ \\
Asian ${ }^{a}$ & $100(70.4)$ \\
Other & $6(4.2)$ \\
\hline Duration of addiction, years & \\
$\leqslant 1$ & $10(7.0)$ \\
$2-5$ & $85(59.9)$ \\
$6-9$ & $27(19.0)$ \\
$10-14$ & $9(6.3)$ \\
$15-18$ & $5(3.5)$ \\
$\geqslant 19$ & $6(4.2)$ \\
\hline
\end{tabular}

a For this study, we used the term 'Asian' to mean South-East Asian, including Indian, Pakistani, Sri Lankan and Bangladeshi people.

It is noteworthy that the majority of patients successfully recruited in the study were from Southall, a ward of the London borough of Ealing with a large population of people with an Indian background. Recent estimates suggest approximately $80 \%$ of the Southall population is Asian or British Asian. The 2001 census indicated the Southall ward population was $75.5 \%$ Asian or British Asian, compared with $24.53 \%$ in the London borough of Ealing.

\section{Opioid detoxification}

The majority of the patients $(n=106 ; 74.6 \%)$ completed successful detoxification in the out-patient or community setting. Overall, 32 patients $(22.5 \%)$ required in-patient treatment to complete detoxification, which included 9 patients (6.3\%) receiving private in-patient treatment, primarily by undergoing rapid opiate detoxification. A small percentage of patients $(2.8 \%)$ completed self-detoxification in the home environment.

The patients were treated with a number of different detoxification regimens: 86 patients (60.6\%) accomplished successful detoxification with buprenorphine as outpatients or in-patients; 30 patients (21.1\%) achieved detoxification with lofexidine; 10 patients (7\%) completed detoxification using methadone; and 16 patients (11.3\%) used other methods (dihydrocodeine, self-detoxification or combination medications, e.g. rapid opiate detoxification). To ensure the absence of opioid use and to prevent a severe withdrawal state related to naltrexone use, a naloxone challenge was used in 114 patients (80.3\%). 


\section{Naltrexone maintenance}

Maintenance treatment with oral naltrexone was given under supervision where possible: 83 patients (58.5\% of cases) were supervised by their parents; 37 patients $(26.1 \%)$ were supervised by their partner; 4 patients $(2.8 \%)$ were supervised by a sibling or friend; 11 patients (7.7\%) selfmedicated with naltrexone; and details of supervision were not known for 7 (4.9\%) patients.

\section{Retention in treatment}

The majority of the patients $(n=79 ; 55.6 \%)$ remained on naltrexone treatment for 4-8 weeks, and 42 patients (29.6\%) remained on treatment for at least 17 weeks (Table 2). The maximum treatment duration at the time of analysis was in excess of 72 weeks.

Reasons for discontinuing naltrexone treatment included lack of supervision, dislike of taking tablets, and lack of motivation to remain abstinent; in many cases, however, no reason was given for discontinuing naltrexone treatment. Most of the patients who left within the first 8 weeks of naltrexone treatment exited the service without prior warning. The most likely presumption was relapse, but other reasons include side-effects and dislike of giving control (through supervised naltrexone administration) to their partner or a relative. The most commonly reported adverse effects were nausea, abdominal pain, nervousness, sleeping difficulties, headache, reduced energy, joint and muscle pain, and sexual dysfunction. A rare laboratory finding was abnormal liver function tests.

\section{Potential predictors for long-term retention on naltrexone}

\section{Univariate analysis}

Progression to stage III (naltrexone maintenance treatment for at least 17 weeks) was used as an indicator of successful control of opioid dependence. The individual effects of each variable on progression to stage III were examined separately using logistic regression. The results, summarised in Table 3, indicate that when examined separately, eight different sociodemographic and addiction-related parameters had a statistically significant effect influencing long-term naltrexone treatment (stage III use).

The results for ethnicity indicate that Asian people were more likely than White people to continue to stage III $(P=0.01)$. The odds of continuing to stage III were more than four times higher for Asian patients when compared with White patients.

\begin{tabular}{|lc|}
\hline \multicolumn{2}{|l|}{ Table 2 Retention in naltrexone treatment } \\
Variable & $n(\%)$ \\
\hline Retention in treatment, weeks \\
$4-8$ weeks \\
$9-20$ weeks & $79(55.6)$ \\
$21-36$ weeks & $21(14.8)$ \\
$37-52$ weeks & $30(21.1)$ \\
$53-72+$ weeks & $7(4.9)$ \\
Retention in treatment by stage & $5(3.5)$ \\
Stage I (1-8 weeks) & $79(55.6)$ \\
Stage II (9-16 weeks) & $21(14.8)$ \\
Stage III ( $\geqslant 17$ weeks) & $42(29.6)$ \\
\hline
\end{tabular}

Employment status analysis indicate that people who were employed or students were nearly three times more likely to achieve long-term naltrexone treatment compared with people who were unemployed $(P=0.01)$.

People who rarely reported feeling bored were more likely to continue to stage III $(P=0.04)$. The odds of continuing to stage III were more than three times higher for people who were never or only occasionally bored compared with people who were bored most of the time. There was also some evidence for a positive effect of motivation, but this result was of borderline statistical significance $(P=0.05)$.

When alcohol intake was examined, there was little difference between the patients who did not drink alcohol and the patients who consumed a small number of units per week. Patients with an alcohol consumption of more than 10 units per week, however, were less likely to continue to stage III $(P=0.01)$. The odds of maintaining on naltrexone therapy to stage III were three times higher in patients who did not drink alcohol compared with patients with heavy alcohol consumption.

The results for cannabis use show that the patients with occasional, frequent or daily cannabis use were less likely to continue on naltrexone treatment than the patients who did not use cannabis $(P=0.04)$.

The results for supervision indicate that the patients living with and having treatment supervised by their parents were more likely to continue to stage III than the patients who were supported by their partner or undergoing self-treatment without supervision.

Addiction duration was a highly significant factor, with a longer duration associated with a decreased likelihood of continuing to stage III $(P=0.008)$.

Age was another significant factor, with younger patients being more likely to continue $(P=0.03)$. A 10-year increase in age was associated with the odds of continuing to stage III halving.

\section{Multivariate analysis}

The multivariate analysis indicated that only alcohol and addiction duration were statistically significant independent predictors for continuation to stage III (Table 4). After adjusting for these two factors, there was no evidence of an effect of ethnicity, employment, boredom, cannabis, supervision or age on continuing to stage III.

There was only a small difference between patients drinking no alcohol and patients drinking less than 10 units per week. The odds of retention in treatment to stage III were over three times smaller in patients who drank 10-40 units of alcohol per week compared with those who drank no alcohol.

The multivariate analysis determined that longer addiction duration was associated with a decreased likelihood of continuing to stage III. The odds of patients with addiction duration of 7 or more years continuing to stage III were a seventh of the odds of patients addicted for 3 years or less continuing to stage III. 


\begin{tabular}{|c|c|c|c|c|}
\hline Variable & $\begin{array}{c}\text { Did not progress } \\
n(\%)\end{array}$ & $\begin{array}{c}\text { Progressed to stage III } \\
n(\%)\end{array}$ & OR $(95 \% \mathrm{Cl})$ & $P$ \\
\hline $\begin{array}{l}\text { Gender } \\
\text { Male } \\
\text { Female } \\
\end{array}$ & $\begin{array}{r}93(70) \\
7(78) \\
\end{array}$ & $\begin{array}{r}39(30) \\
2(22) \\
\end{array}$ & $\begin{array}{c}1 \\
0.68(0.14-3.43) \\
\end{array}$ & 0.64 \\
\hline $\begin{array}{l}\text { Marital status } \\
\text { Unmarried } \\
\text { Married }\end{array}$ & $\begin{array}{l}70(67) \\
24(77)\end{array}$ & $\begin{array}{r}34(33) \\
7(23)\end{array}$ & $\begin{array}{c}1 \\
0.60(0.24-1.53) \\
\end{array}$ & 0.29 \\
\hline $\begin{array}{l}\text { Ethnicity } \\
\text { White } \\
\text { Asian or other }\end{array}$ & $\begin{array}{l}32(89) \\
68(65)\end{array}$ & $\begin{array}{r}4(11) \\
37(35)\end{array}$ & $\begin{array}{c}1 \\
4.36(1.43-13.3)\end{array}$ & 0.01 \\
\hline $\begin{array}{l}\text { Employment status } \\
\text { Unemployed } \\
\text { Employed or student }\end{array}$ & $\begin{array}{l}83(76) \\
17(53)\end{array}$ & $\begin{array}{l}26(24) \\
15(47)\end{array}$ & $\begin{array}{c}1 \\
2.86(1.24-6.41)\end{array}$ & 0.01 \\
\hline $\begin{array}{l}\text { Boredom } \\
\text { None or occasional } \\
\text { Frequent } \\
\text { Most of the time }\end{array}$ & $\begin{array}{l}16(53) \\
41(72) \\
43(80)\end{array}$ & $\begin{array}{l}14(47) \\
16(28) \\
11(20)\end{array}$ & $\begin{array}{c}1 \\
0.44(0.18-1.12) \\
0.29(0.11-0.78)\end{array}$ & 0.04 \\
\hline $\begin{array}{l}\text { Motivation } \\
\text { Very good } \\
\text { Fair or poor }\end{array}$ & $\begin{array}{l}63(66) \\
37(82)\end{array}$ & $\begin{array}{r}33(34) \\
8(18)\end{array}$ & $\begin{array}{c}1 \\
0.41(0.17-0.99)\end{array}$ & 0.05 \\
\hline $\begin{array}{l}\text { Sleep disturbance } \\
\text { Nil or mild } \\
\text { Moderate } \\
\text { Severe }\end{array}$ & $\begin{array}{l}38(69) \\
38(72) \\
24(73)\end{array}$ & $\begin{array}{r}17(31) \\
15(28) \\
9(27)\end{array}$ & $\begin{array}{c}1 \\
0.88(0.39-2.02) \\
0.83(0.32-2.18)\end{array}$ & 0.92 \\
\hline $\begin{array}{l}\text { Alcohol intake } \\
\text { None } \\
<10 \text { units/week } \\
10-40 \text { units/week }\end{array}$ & $\begin{array}{l}33(35) \\
23(59) \\
44(86)\end{array}$ & $\begin{array}{r}18(35) \\
16(41) \\
7(14)\end{array}$ & $\begin{array}{c}1 \\
1.27(0.54-3.01) \\
0.29(0.11-0.78)\end{array}$ & 0.01 \\
\hline $\begin{array}{l}\text { Cannabis use } \\
\text { None } \\
\text { Occasional } \\
\text { Frequent or daily }\end{array}$ & $\begin{array}{l}27(57) \\
38(81) \\
35(75)\end{array}$ & $\begin{array}{r}20(43) \\
9(19) \\
12(26)\end{array}$ & $\begin{array}{c}1 \\
0.32(0.12-0.71) \\
0.46(0.19-1.11)\end{array}$ & 0.04 \\
\hline $\begin{array}{l}\text { Cocaine use } \\
\text { None } \\
\text { Occasional or frequent }\end{array}$ & $\begin{array}{l}93(72) \\
7(64) \\
\end{array}$ & $\begin{array}{r}37(28) \\
4(36) \\
\end{array}$ & $\begin{array}{c}1 \\
1.44(0.40-5.20) \\
\end{array}$ & 0.58 \\
\hline $\begin{array}{l}\text { Supervision } \\
\text { Parent } \\
\text { Partner } \\
\text { Self or other }\end{array}$ & $\begin{array}{l}50(61) \\
31(84) \\
12(80)\end{array}$ & $\begin{array}{r}32(39) \\
6(16) \\
3(20)\end{array}$ & $\begin{array}{c}1 \\
0.30(0.11-0.81) \\
0.39(0.10-1.49)\end{array}$ & 0.03 \\
\hline $\begin{array}{l}\text { Addiction duration, years } \\
\begin{array}{l}1-3 \\
4-6 \\
\geqslant 7\end{array}\end{array}$ & $\begin{array}{l}34(59) \\
34(71) \\
32(91)\end{array}$ & $\begin{array}{c}24(41) \\
14(29) \\
3(9)\end{array}$ & $\begin{array}{c}1 \\
0.58(0.26-1.31) \\
0.13(0.04-0.48)\end{array}$ & 0.008 \\
\hline $\mathrm{Age}^{\mathrm{a}}$ & $27(8)$ & $24(5)$ & $0.51(0.27-0.94)$ & 0.03 \\
\hline
\end{tabular}

${ }^{a}$ Odds ratios given for a 10-year increase in age.

\section{Discussion}

One key finding from this study was the low retention in treatment for patients receiving naltrexone maintenance in a community setting: only $29.6 \%$ of patients remained in treatment for 17 weeks or more. The multivariate analysis identified only two significant independent predictors for longer-term retention in treatment: short duration of addiction ( $\leqslant 3$ years) and no or only low intake of alcohol $(<10$ units/week).

There were limitations associated with the study methodology, which should be taken into consideration. The analyses were retrospective in nature, and the sample size was relatively small, especially in view of the number of different variables evaluated. The analysis was conducted on 142 of 220 people dependent on opioids who were initiated on naltrexone treatment at the treatment centre during the study period. The people excluded from the evaluation may have revealed useful information on predictors for longerterm retention in treatment, but the population analysed reflects the patients with sufficient motivation to remain on treatment for at least 4 weeks - that is, the relevant patient population for the community-based clinical treatment setting.

The outcome measure to assess efficacy of naltrexone in the community setting was retention in treatment. In this study, of the 142 evaluable patients, $55.6 \%$ remained in 


Table $4 \begin{aligned} & \text { Independent predictors for successful long-term } \\
& \text { retention in treatment (progression to stage III) } \\
& \text { identified through multivariate analysis }\end{aligned}$
\begin{tabular}{lcc} 
Variable & OR $(95 \% \mathrm{Cl})$ & $P$ \\
\hline $\begin{array}{l}\text { Alcohol use } \\
\text { Nil }\end{array}$ & 1 & \\
$<10$ units/week & $1.36(0.55-3.36)$ & \\
$10-40$ units/week & $0.31(0.11-0.87)$ & 0.02 \\
\hline $\begin{array}{l}\text { Duration of addiction, years } \\
1-3\end{array}$ & 1 & \\
$4-6$ & $0.53(0.23-1.24)$ & \\
$\geqslant 7$ & $0.14(0.04-0.52)$ & 0.01 \\
\end{tabular}

treatment for only 4-8 weeks and $29.6 \%$ remained in treatment for 17 weeks or more (stage III). It could be argued that since 220 patients initiated naltrexone treatment following opioid detoxification, the retention in treatment for 17 weeks or more for patients on the programme was even lower $(42 / 220,19.1 \%)$.

These results are lower than those recorded in naltrexone clinical trials where the mean period for retention in treatment has been 17-30 weeks. ${ }^{8,9}$ The results from this study, however, are broadly similar to those achieved in a US community-based programme using behavioural therapy to augment naltrexone; ${ }^{10}$ in this study, retention in treatment for 36 patients dependent on heroin was $69.4 \%$ at 4 weeks, $44.4 \%$ at 12 weeks and $22.2 \%$ at 24 weeks. A public out-patient clinic in Australia analysed outcomes in 981 patients and reported a mean retention period of 9 weeks. ${ }^{11}$

In view of the relatively low long-term rates of retention in treatment achieved with naltrexone in a community setting, it is important to identify which patient subgroups are most likely to benefit from naltrexone treatment and which may need enhanced support to achieve abstinence despite fulfilling the treatment criteria (e.g. strong motivation, availability of supervision of treatment).

Review of the literature suggests very few studies have identified potential predictors for favourable outcome with naltrexone therapy. One early US study determined that patients in employment or married at the start of naltrexone treatment were more likely to stay in treatment for longer. ${ }^{12}$ A more recent US study reported that on multiple regression analysis, poorer outcome (shorter retention in treatment) was associated with methadone use and heavier use of heroin before treatment. ${ }^{13}$ A study from Spain found that men had a better prognosis than women: for 1432 people dependent on opioids (83.1\% males, $16.9 \%$ females) receiving naltrexone treatment over a period of 12 years, a significantly higher 1-year retention rate was found for men than for women (30.9\% v. 23.9\%, $P=0.0038)$. The authors concluded that these differences were due to sociocultural differences, with women having less economic independence, having an addict as a partner, or having less help from their partner. ${ }^{14}$

The premise for this retrospective analysis was that Asian people appeared to have a better outcome on naltrexone treatment compared with White people. Asian people constituted just over $70 \%$ of the patients enrolled into this naltrexone maintenance programme. Univariate analysis found that Asian and other minority ethnic people were significantly more likely than White people to achieve successful retention in treatment, being over four times more likely to be in treatment at 17 weeks or more. Possible reasons for a favourable outcome in Asian people include the following:

- family support during treatment, especially supervisory input during treatment

- motivation by family and possibly some reward system

- family offering social and financial support, e.g. private detoxification and personal allowances

- support network, e.g. voluntary sector and GP

- motivation to become drug-free and be employed, often within the family business

- relatively lower rate of alcohol use

- early engagement in treatment (approximately 67\% of Asian patients had an addiction history of 1-5 years).

However, these factors do not exclusively apply to Asian patients and may very well apply to White patients in different settings, locations and circumstances.

The importance of many of the considerations listed above was confirmed in the univariate analysis, whereby a significant effect was found for Asian or other minority ethnic status, employment or student status, low rate of boredom, motivation (borderline significance), supervision, addiction duration, cannabis use, younger age and lower alcohol intake favouring longer-term retention in treatment to 17 weeks or more (stage III). Subsequent multivariate analysis confirmed the considerable interrelationships between these variables. Sociodemographic factors such as ethnicity, employment status and supervision (reflecting family circumstances), boredom scores, cannabis use and age were no longer found to be significant influencers of naltrexone treatment efficacy.

Following multivariate analysis, duration of addiction of 7 or more years was identified as a significant predictor for poor outcome in terms of retention in treatment. This suggests that patients with prolonged addiction, even if well motivated to maintain abstinence, may require more intensive treatment strategies. It could be postulated that these patients have fewer close family ties following prolonged opioid addiction and therefore need greater support to continue with naltrexone treatment.

The exclusion criteria for this study included people with alcohol dependence or harmful use of alcohol, making the identification of a significant independent effect for alcohol use on retention in treatment for these patients of particular relevance. Additional support such as alcohol counselling may improve retention in treatment for patients who are heavy drinkers or report increasing alcohol intake during naltrexone treatment.

\section{Acknowledgements}

The authors wish to thank Paul Bassett, Statistician, who assisted in the final data analysis and Josie Saulter, Information Pharmacist, who helped with drafting the manuscript. 


\section{About the authors}

Zubair A. Chaudhry is Associate Specialist Psychiatrist at the Central and North West London NHS Foundation Trust. Javaid Sultan is Consultant Psychiatrist at the Berkshire Healthcare NHS Foundation Trust. Farrukh Alam is Consultant Psychiatrist and Clinical Director at the Central and North West London NHS Foundation Trust.

\section{References}

1 National Institute for Health and Clinical Excellence. Naltrexone for the Management of Opioid Dependence. NICE Technology Appraisal Guidance 115. NICE, 2007.

2 Luty J. What works in drug addiction? Adv Psychiat Treat 2003; 9: 280-8.

3 Adi $Y$, Juarez-Garcia A, Wang D, et al. Oral naltrexone as a treatment for relapse prevention in formerly opioid-dependent drug users: a systematic review and economic evaluation. Health Technol Assess 2007; 11: iii-iv, 1-85

4 Minozzi S, Amato L, Vecchi S, Jowett S, Frew E, Day E, et al. Oral naltrexone maintenance treatment for opioid dependence. Cochrane Database Syst Rev 2006; 25: CD001333.

5 Roozen HG, de Waart R, van der Windt DA, Davoli M, Kirchmayer U, Verster A. A systematic review of the effectiveness of naltrexone in the maintenance treatment of opioid and alcohol dependence. Eur Neuropsychopharmacol 2006; 16: 311-23.

6 Johansson BA, Berglund M, Lindgren A. Efficacy of maintenance treatment with naltrexone for opioid dependence: a meta-analytical review. Addiction 2006; 101: 491-503.
7 Kirchmayer U, Davoli M, Verster AD, Amato L, Ferri A, Perucci CA. A systematic review on the efficacy of naltrexone maintenance treatment in opioid dependence. Addiction 2002; 97: 1241-9.

8 Cornish JW, Metzger D, Woody GE, Wilson D, McLellan AT, Vandergrift B, et al. Naltrexone pharmacotherapy for opioid dependent federal probationers. J Subst Abuse Treat 1997; 14: 529-34.

9 Rawson RA, Glazer M, Callahan EJ, Liberman RP. Naltrexone and behavior therapy for heroin addiction. NIDA Res Monogr 1979; 25: 2643.

10 Nunes EV, Rothenberg JL, Sullivan MA, Carpenter KM, Kleber HD. Behavioral therapy to augment oral naltrexone for opioid dependence: a ceiling on effectiveness? Am J Drug Alcohol Abuse 2006; 32: 503-17.

11 Bartu A, Freeman NC, Gawthorne GS, Allsop SJ, Quigley AJ. Characteristics, retention and readmissions of opioid-dependent clients treated with oral naltrexone. Drug Alcohol Rev 2002; 21: 335-40.

12 Greenstein RA, Evans BD, McLellan AT, O'Brien CP. Predictors of favorable outcome following naltrexone treatment. Drug Alcohol Depend 1983; 12: 173-80.

13 Sullivan MA, Rothenberg JL, Vosburg SK, Church SH, Feldman SJ, Epstein EM, et al. Predictors of retention in naltrexone maintenance for opioid dependence: analysis of a stage I trial. Am J Addict 2006; 15: 150-9.

14 Ochoa E, Madoz-Gúrpide A, Salvador E. Diferencias de genero en e tratamiento de la dependencia de opiaceos con naltrexone. [Gender differences in the treatment of the opiate dependence with naltrexone.] Actas Esp Psiquiatr 2008; 36: 197-20. 